\title{
KINERJA BANK UMUM KONVENSIONAL DI ERA REFORMASI
}

\author{
Raden Ai Lutfi Hidayat \\ Universitas Pamulang, Banten \\ lhidayat20@gmail.com
}

\begin{abstract}
Submitted: $02^{\text {nd }}$ Sept 2019/ Edited: $07^{\text {th }}$ November 2019/ Issued: $01^{\text {st }}$ January 2020
Cited on: Hidayat, R. A. L. (2020). KINERJA Bank Umum Konvensional Di Era Reformasi. SCIENTIFIC JOURNAL OF REFLECTION: Economic, Accounting, Management and Business, 3(1), 81-90.

DOI: $10.37481 /$ sjr.v3i1.128

https://doi.org/10.37481/sjr.v3i1.128
\end{abstract}

\begin{abstract}
Banking institutions are one pillars of the country's economy. His role as a regulator of financial traffic is the cause. Therefore, banks cannot fail, especially bankruptcy. The impact is triggering inflation and deflation that disrupt the economic system and crisis. A bitter experience occurred in 1998. The state suffered losses and triggered a social crisis. Since then, Indonesia has continued to maintain banking institutions to remain healthy and stable. This study aims to present information on banking performance, so it can be useful for parties. Proof efforts use a quantitative approach. Research data sourced from OJK. The results showed that the bank's performance was relatively good. But the last ten years showed a downward trend. The bank is able to maintain capital adequacy, good management of credit burden and risk, so as to increase interest income. But this has not been able to optimize profit and liquidity.
\end{abstract}

Keywords : Capital, Profitability, Liquidity

\section{PENDAHULUAN}

Bank adalah satu-satunya unit ekonomi yang dijadikan indikator stabilitas suatu negara. Perannya memberikan dampak yang besar terhadap perputaran uang, oleh karenanya sedikit saja melakukan kesalahan maka berdampak pada inflasi atau deflasi, yang pasti dapat merugikan negara dan masyarakat. Oleh karenanya, lembaga keuangan seperti bank diatur secara khusus oleh UU no. 23 tahun 1999 dan UU no. 10 tahun 1998. Secara tegas bank disebutkan sebagai instrumen ekonomi negara yang mengatur lalu lintas keuangan (moneter) yang mampu mempengaruhi laju perputaran ekonomi (De Jonghe, 2010). Dengan kata lain, bank merupakan instrumen dari stabilitas ekonomi. Kenjegalieva, et al (2009) mengemukakan, kacaunya ekonomi di di Amerika dan Eropa tahun 2008, bahkan Yunani mengalami gagal bayar karena jatuhnya dunia perbankan. Artinya, bank merupakan simbol kekuatan dari suatu negara, jika ia rapuh 
maka rapuh pula struktur ekonomi negara, dan itu sangat berpotensi terhadap terjadinya krisis. Sejarah membuktikan, hal terburuk dari krisis moneter adalah konflik.

Untuk itu penting bagi pihak-pihak berwenang, khususnya pemerintah untuk menjaga dan merawat perbankan agar selalu sehat, salah satunya dengan memperhatikan kinerja bank. Rashedul \& Israt (2012), kinerja bank menunjukkan seberapa baik memanfaatkan dana pihak ketiga (DPK), karena mereka pun dituntut untuk membayar bunga atas pemanfaatan tersebut. Bank tidak boleh mengendurkan produktivitas, semua potensi sumber daya yang ada harus dimaksimalkan, bila perlu minimalisir beban operasional sehingga profitabilitas meningkat.

Profitabilitas sering dijadikan indikator di dalam melihat kinerja bank. Mengingat, rasio tersebut menunjukkan seberapa menguntungkannya bank. Apakah mereka sukses menjalankan usaha, benar menjalankan prosedur, memiliki kepercayaan masyarakat, dan sebagainya. Asma'Rashidah et al (2011), profitabilitas itu istimewa, karena ia menjelaskan baiknya manajemen bank dalam mengelola usaha, minim risiko, maksimal penjualan, nasabah yang besar, dan memiliki masa depan.

Dalam banyak kajian, kinerja bank selalu dikaitkan dengan profitabilitas. Entah karena keuntungan adalah kemampuan dari suatu usaha atau masyarakat percaya, bahwa perusahaan berdiri di atas alasan materil. Maka, jika suatu bank lemah dalam meningkatkan laba, sesungguhnya tidak ada harapan di masa mendatang (Sufian, 2010; Wasiuzzaman \& Tarmizi, 2010). Namun hal yang diperlukan adalah tidak menjadikan profitabilitas sebagai satu alasan mencari investasi, akan tetapi lebih pada pengembangan bisnis (Acaravci \& Çalim, 2013).

Pendapat lain mengatakan, profitabilitas adalah tujuan utama dari suatu bisnis, maka atas dasar tersebut suatu perusahaan dikatakan berkinerja. Tentu tidak ada satu indikator yang paling pantas untuk menggambarkan betapa berprestasinya suatu perusahaan kecuali keuntungan (Lee, et al., 2014). Hashem (2016), profitabilitas adalah indikator yang dengannya perusahaan mampu menyelesaikan likuiditasnya, dengannya perusahaan mampu mengoptimalkan aktivitasnya, dengannya perusahaan mampu meningkatkan kepercayaan investor, dan dengannya mampu menjadi simbol kepercayaan atas dana masyarakat yang disimpan. Baltaci (2014), tidak sedikit bank bekerja keras melakukan segala cara hanya untuk mendapatkan status profitabilitas, dengan itu bank mendapatkan simbol kejayaan. 
Selain itu, dalam tataran operasional bank membutuhkan modal yang cukup, bahkan di Indonesia dalam UU no. 10 tahun 1998 bank diwajibkan memiliki kecukupan modal minimal. Hal tersebut sebagai standar ganda di dalam menjaga risiko-risiko perbankan, seperti ras. Shingjergji \& Hyseni (2015), bagi bank modal adalah nafas. Mengingat unit utama usaha bank adalah pembiayaan atau kredit, yang pastinya menggunakan uang. Oleh karenanya, memastikan kecukupan modal adalah fundamental. Abdillah, dkk (2016), sesungguhnya kecukupan modal diwajibkan agar bank dapat menyalurkan kredit secara maksimal, sehingga bank mendapatkan banyak keuntungan (dari bunga pinjaman).

Bagi bank memiliki modal besar adalah faktor utama dalam menyalurkan kredit, dan dari kredit itu bank mendapatkan keuntungan. Oleh karenanya, tidak ada jalan lain kecuali bank melakukan strategi paralel, di saat yang sama bang menghimpun dan menyalurkan dana kepada masyarakat, dengan cara itu bank mendapatkan profitabilitas. Selain itu, modal juga sangat penting bagi optimalisasi pendapatan agar likuiditas perusahaan terjaga. Sangat sulit bagi bank untuk dapat menyelesaikan likuiditasnya jika modal kurang cukup bagi pendanaan. Likuiditas membutuhkan profit yang stabil, dan profit dapat dipenuhi jika unit usaha bank lancar.

Anbar \& Alper (2011), terdapat hubungan yang erat antara modal, profitabilitas, dan likuiditas. Di mana, modal menjadi sumber bagi efektivitas usaha, dengan itu menghasilkan laba. Kemudian lama digunakan untuk menyelesaikan kewajibankewajiban perusahaan (likuiditas). Baiknya likuiditas perusahaan akan melahirkan kepercayaan pihak-pihak berkepentingan (nasabah dan investor), yang pada gilirannya modal bank bertambah.

Konsep di atas adalah sistem yang tidak dapat dipisahkan, bahkan kinerja bank sangat erat kaitannya dengan modal, keuntungan, dan likuiditas. Sudah tentu, profitabilitas wajib dicapai agar dapat menjadi jembatan yang baik bagi pertumbuhan modal dan likuiditas. Munteanu (2012), di negara kapitalis bank disaratkan likuid, dan untuk mencapai hal tersebut maka bank mengoptimalkan penyaluran kredit agar profitabilitas bertambah. Kemal (2011), dalam kinerja bank ada tiga faktor yang selalu menjadi perhatian di antaranya modal yang cukup, pertumbuhan profitabilitas stabil, dan menjaga likuiditas. Terpenuhinya ketiga indikator tersebut dapat menghantarkan bank menjadi lembaga keuangan paling dipercaya publik. 
Vol. 3, No. 1, January 2020

\section{LANDASAN TEORI}

Berkinerja merupakan keniscayaan dalam suatu organisasi profit. Tidak peduli alasan apapun, bahwa perusahaan harus menguntungkan, bahwa perusahaan harus beroperasi dengan baik, bahwa perusahaan harus mencapai target, bahwa produk yang jual harus laku, dan sebagainya. García-Meca, et al (2015), dalam industri perbankan tidak dikenal istilah gagal, bank harus untung, kenapa? Karena bank harus membayar bunga deposito, itu yang pokok. Oleh karenanya, bank harus berkinerja tinggi, apa artinya? Bank harus baik menyalurkan kredit, dan di saat yang sama bank harus mengendalikan beban serta risiko. García-Meca, et al (2015) menambahkan, oleh karenanya bank harus meningkatkan kompleksitas aktivitas, termasuk memanfaatkan layanan digital. Bank harus bertransformasi menjadi lembaga yang aplikatif bagi kehidupan sehari-hari masyarakat. Joseph, et al (2005) menambahkan, salah satu indikator kinerja bank non finansial yang utama adalah kepercayaan nasabah. Bank bisa mulai dari pelayanan yang memuaskan, bank hadir sebagai layanan finansial di setiap lini transaksi nasabah, seperti transaksi berbelanja, berkendara, membayar tagihan, pendidikan, transportasi, dan semu hal lain.

Penjelasan di atas menegaskan bahwa kinerja adalah keniscayaan yang harus dicapai oleh perbankan, selain memiliki peran strategis dalam ekonomi nasional, bank juga memiliki tujuan yang harus dicapai. Dengan memaksimalkan penyaluran kredit dan menjaga risikonya, maka diharapkan pendapatan bunga pinjaman meningkat. Selain itu, bank dapat melakukan tindakan efisiensi agar beban-beban yang tidak perlu dapat dihilangkan, sehingga Perolehan laba menjadi lebih besar. Dengan baiknya ukuran profitabilitas yang dibarengi pengendalian risiko dan efisiensi maka di harapkan kinerja perusahaan menjadi lebih baik.

Selain itu, kinerja bank juga menunjukkan seberapa baik struktur organisasi dan kemampuan manajemen dalam bekerja. Artinya, kinerja adalah hasil kerja dari para struktural organisasi yang memanfaatkan manajemen sebagai alat mengelola usaha bank. Baiknya seluruh stakeholder internal merupakan indikator baiknya kinerja, namun sebaliknya jika buruk maka buruk pula kinerja. Tentu keadaan ini harus diperhatikan oleh pihak eksternal yang berkepentingan seperti pemerintah, investor, dan masyarakat agar tercipta stabilitas bersama. 
Banyak riset membuktikan bahwa profitabilitas adalah ukuran yang populer dalam menilai kinerja suatu bank, dan bahkan bagi perusahaan profit lain. Secara eksplisit profit diartikan sebagai kemampuan bank di dalam menghasilkan laba, yang artinya bank dalam proses menghasilkan laba dituntut baik dalam menjalankan manajemen, baik dalam menjual produk, baik dalam memberikan pelayanan, baik dalam mengendalikan kredit bermasalah, baik dalam mengendalikan beban operasional, dan lain sebagainya, khususnya manajemen sumber daya manusia. Asma'Rashidah et al (2011) mengatakan, aspek profit dijadikan dasar bagi bank dalam menyelesaikan likuidasinya, terutama jangka pendek dan menengah. Artinya, profitabilitas adalah penopang bagi struktur perusahaan dalam hal ini menjaga stabilitas modal. Tentu, agar bank maksimal di dalam menghasilkan laba, maka kecukupan modal harus terjamin. Hashem (2016) menjelaskan profitabilitas adalah wajah baik bank, yang dengannya orang percaya bahwa bank profesional dan sebagainya. Oleh karena itu, bank berusaha keras untuk menghasilkan keuntungan sebesar-besarnya.

Selain profit, modal dan likuiditas menjadi ukuran bagi kinerja bank. Shingjergji \& Hyseni (2015), menjalani bisnis keuangan harus banyak modal, setidaknya bank memiliki cadangan 3 (tiga) kali lipatnya dari dana simpanan. Hal tersebut perlu dilakukan sebagai antisipasi jika sewaktu-waktu terjadi kondisi yang tidak diduga, namun bank tetap bisa menjaga keadaan tetap stabil. Sedangkan Munteanu (2012) menyatakan peran likuiditas bagi kinerja bank sangat penting, terutama dari sudut pandang investasi. Bahwa bank tidak bisa menghindar dari kebutuhan dana, dan dengan memastikan likuiditasnya baik maka investor akan percaya.

\section{METODE PENELITIAN}

Konsep dasar penelitian ini adalah tinjauan empiris yakni menggunakan data statistik OJK dari tahun 2005 - 2019. Hal tersebut bertujuan untuk mengemukakan informasi perjalanan bank di masa era reformasi. Sejauh mana pertumbuhan kinerja bank di lihat dari 3 (tiga) indikator utama, yakni modal, profitabilitas, dan likuiditas. Selanjutnya, untuk menyelesaikan konsep di atas digunakan pendekatan kuantitatif dengan pertimbangan sebagai cara yang mudah dipahami oleh pembaca, berupa angka dan pembahasan yang jelas. 
Proses pengujian dilakukan menggunakan analisis regresi dengan pengujian deskriptif, uji asumsi klasik, dan uji regresi linear. Pada tahapannya pengujian dilakukan mengikuti prosedur ilmiah yang telah ditetapkan, sehingga hasil penelitian akan memberikan gambaran yang lebih baik. Adapun alasan menggunakan regresi sebagai analisis adalah cara sederhana di dalam menyajikan informasi sehingga mudah dipahami.

\section{HASIL PENELITIAN}

Tabel 1. Kinerja Bank Umum Konvensional di Indonesia (Dalam Persen)

\begin{tabular}{cccccccc}
\hline No & Tahun & CAR & ROA & BOPO & NIM & LDR & LIKUIDITAS \\
\hline 1 & 2004 & 19.42 & 3.46 & 76.64 & 0 & 49.95 & 0 \\
2 & 2005 & 19.30 & 2.55 & 89.5 & 0 & 59.66 & 0 \\
3 & 2006 & 21.27 & 2.64 & 86.98 & 0 & 61.56 & 0 \\
4 & 2007 & 19.30 & 2.78 & 84.05 & 0 & 66.32 & 0 \\
5 & 2008 & 16.76 & 2.33 & 88.59 & 0 & 74.58 & 0 \\
6 & 2009 & 17.42 & 2.60 & 86.63 & 0 & 72.88 & 0 \\
7 & 2010 & 17.18 & 2.86 & 86.14 & 0 & 75.21 & 0 \\
8 & 2011 & 16.05 & 3.03 & 85.42 & 0 & 78.77 & 0 \\
9 & 2012 & 17.43 & 3.11 & 74.10 & 5.49 & 83.58 & 18.45 \\
10 & 2013 & 18.13 & 3.08 & 74.08 & 4.89 & 89.70 & 15.77 \\
11 & 2014 & 19.57 & 2.85 & 76.29 & 4.23 & 89.42 & 16.24 \\
12 & 2015 & 21.39 & 2.32 & 81.49 & 5.39 & 92.11 & 16.70 \\
13 & 2016 & 22.93 & 2.23 & 82.22 & 5.63 & 90.70 & 17.50 \\
14 & 2017 & 23.18 & 2.45 & 78.64 & 5.32 & 90.04 & 18.56 \\
15 & 2018 & 22.97 & 2.55 & 77.86 & 4.14 & 94.78 & 14.96 \\
16 & 2019 & 23.54 & 2.48 & 80.65 & 4.90 & 93.96 & 15.37 \\
\hline \multicolumn{2}{r}{ Rata-rata } & 19.12 & 2.71 & 81.83 & 5.00 & 78.95 & 16.69 \\
\hline
\end{tabular}

Sumber: OJK (Statistik Perbankan Indonesia), 2019

Data di atas memperlihatkan indikator-indikator kinerja bank selama era reformasi (2004-2019), di mana:

1. Tren modal bank konvensional di Indonesia selama 16 tahun terakhir mengalam meningkat.

2. Tren ROA mengalami fluktuasi, khususnya sejak tahun 2014 mengalami tren penurunan.

3. Tren BOPO mengalami fluktuasi, khususnya sejak tahun 2012 mengalami tren penurunan. 
4. Tren NIM menunjukkan kinerja yang stabil selama kurun waktu periode 20122019.

5. Tren LDR mengalami peningkatan yang baik di era reformasi.

6. Tren likuiditas menunjukkan fluktuasi, namun pada tahun 2018-2019 mengalami penurunan.

Merujuk data di atas, dapat dikemukakan bahwa modal dan likuiditas bank umum konvensional Indonesia selama era reformasi menunjukkan peningkatan yang baik, namun kedua hal tersebut belum dapat linear dengan peningkatan ROA dan NIM, terlebih BOPO belum optimal. Keadaan ini menegaskan, sejak krisis tahun 1998 bank terus berupaya meningkatkan kinerja dengan memaksimalkan aspek modal dan likuiditas, namun faktor eksternal menjadi tantangan hebat, terutama era digital. Bank tidak menampik adanya perubahan model transaksi, di mana banyak perusahaan non bank yang juga ikut bersaing dalam kegiatan transaksi misalnya financial teknologi. Sehingga dari sisi transaksi bank tidak lagi leluasa, namun yang masih bisa dioptimalkan adalah penyaluran kredit.

Hasil olah data menunjukkan:

1. Modal berpengaruh signifikan terhadap ROA

Perhitungan statistik menunjukkan modal memiliki nilai regresi sebesar 0,507 dengan nilai signifikansi 0.045 . temuan ini sejalan dengan data OJK, bahwa pertumbuhan modal baik selama 16 tahun terakhir. Oleh karena itu, bank menjadi leluasa di dalam menyalurkan kredit yang berdampak pada meningkatnya pendapatan dari bunga kredit. Tentu fakta ini perlu ditanggapi dengan benar, jajaran pimpinan harus memetakan tindakan apa yang harus dilakukan untuk mempertahankan dan meningkatkan keunggulan saat ini, sehingga di masa mendatang tidak tergerus oleh persaingan.

2. ROA tidak berpengaruh signifikan terhadap Likuiditas

Fakta statistik menunjukkan bahwa ROA belum dapat menjelaskan likuiditas di taraf yang berarti, dengan nilai regresi sebesar 0.223 dan nilai signifikansi 0.406. Temuan ini cukup representatif dari data awal, bahwa pertumbuhan laba yang tidak stabil akan mengganggu likuiditas bank itu sendiri. Tentu hal tersebut dipengaruhi oleh faktor-faktor yang sudah diketahui, dan bank harus segera 
mengatasi masalah tersebut. melakukan penyesuaian terhadap era digital adalah salah satu cara yang tepat di era reformasi.

3. Likuiditas berpengaruh signifikan terhadap Modal

Olah data menunjukkan nilai regresi likuiditas terhadap modal sebesar 0.560 dan nilai signifikansi 0.024. Perhitungan statistik ini menegaskan, jika likuiditas memiliki peran penting terhadap kepercayaan pihak-pihak. Masyarakat tentu akan senang menitipkan dananya dengan jaminan likuiditas bank harus baik, terlebih pihak investor. Bagi mereka, cukup sederhana cara berpikir, suatu perusahaan layak diberikan dana jika bank tersebut mampu membayar hutang dan dapat memberikan keuntungan. Jika salah satunya seperti likuiditas kurang baik maka akan menghilangkan kepercayaan.

\section{KESIMPULAN}

Sisi modal dan likuiditas bank konvensional di Indonesia selama periode reformasi sudah baik, namun hal kurang baiknya dari sisi efek profitabilitas. Faktanya, bank di Indonesia belum dapat menunjukkan kinerja yang baik dalam menghasilkan laba sehingga mampu menyelesaikan likuiditasnya dengan baik. Tentu keadaan ini menjadi perhatian penting bagi jajaran CEO untuk meninjau kembali apa yang harus dilakukan di era globalisasi. Mengingat persaingan sangat ketat dan nasabah sudah berubah sudut pandangnya terhadap lembaga perbankan. Mereka tidak lagi ambil pusing dengan transaksi karena banyak perusahaan yang menghadirkan kemudahan.

Bank harus segera mengambil sikap, bagaimana ROA dan sejenisnya dapat memaksimalkan kemampuan perusahaan dalam menyelesaikan likuiditas secara berarti. Melakukan penyesuaian korporasi terhadap digitalisasi adalah keharusan. Mungkin bank dapat menciptakan produk digital yang lebih fleksibel dan terhubung dengan semua kebutuhan masyarakat.

Selain itu, bank perlu memaksimalkan alat likuiditas seperti LDR, namun tetapi hati-hati. Mengingat NPL akan membayangi kegiatan LDR, bank harus memiliki sistem yang handal. Sistem yang mampu mendeteksi segala potensi kerugian dan mampu mencegah terjadinya kerugian atau meminimalisir kerugian. Dengan memaksimalkan modal dan likuiditas yang baik bank akan dapat mendongkrak profitabilitas, yang pada gilirannya dapat meningkatkan kinerja bank. 
Vol. 3, No. 1, January 2020

\section{DAFTAR PUSTAKA}

Abdillah, R., Hosen, M. N., \& Muhari, S. (2016). THE DETERMINANTS FACTOR OF ISLAMIC BANK'S PROFITABILITY AND LIQUIDITY IN INDONESIA. Knowledge Horizons. Economics, 8(2), 140.

Acaravci, S. K., \& Çalim, A. E. (2013). Turkish banking sector's profitability factors. International Journal of Economics and Financial Issues, 3(1), 27-41.

Anbar, A., \& Alper, D. (2011). Bank specific and macroeconomic determinants of commercial bank profitability: Empirical evidence from Turkey. Business and economics research journal, 2(2), 139-152.

Asma'Rashidah Idris, F. F. A., Asari, H., Taufik, N. A. A., Salim, N. J., Mustaffa, R., \& Jusoff, K. (2011). Determinant of Islamic banking institutions' profitability in Malaysia. World Appl. Sci. J, 12, 01-07.

Baltaci, N. (2014). Turkish banking sector: the analysis of macroeconomics indicators and bank profitability with panel data approach. Journal of Academic Research in Economics (JARE), 6(1), 82-92.

De Jonghe, O. (2010). Back to the basics in banking? A micro-analysis of banking system stability. Journal of financial intermediation, 19(3), 387-417.

García-Meca, E., García-Sánchez, I. M., \& Martínez-Ferrero, J. (2015). Board diversity and its effects on bank performance: An international analysis. Journal of Banking \& Finance, 53, 202-214.

Hashem, H. Y. M. (2016). Determinants of Egyptian Banking Sector Profitability: Time-Series Analysis from 2004-2014. International Journal of Business and Economic Sciences Applied Research (IJBESAR), 9(2), 73-78.

Joseph, M., Allbright, D., Stone, G., Sekhon, Y. K., \& Tinson, J. (2005). Importanceperformance analysis of UK and US bank customer perceptions of service delivery technologies. International Journal of Financial Services Management, 1(1), 66-88.

Kemal, M. U. (2011). Post-merger profitability: A case of Royal Bank of Scotland (RBS). International Journal of Business and Social Science, 2(5), 157-162.

Kenjegalieva, K., Simper, R., Weyman-Jones, T., \& Zelenyuk, V. (2009). Comparative analysis of banking production frameworks in Eastern European financial markets. European journal of operational research, 198(1), 326-340.

Lee, C. C., Yang, S. J., \& Chang, C. H. (2014). Non-interest income, profitability, and risk in banking industry: A cross-country analysis. The North American Journal of Economics and Finance, 27, 48-67.

Munteanu, I. (2012). Bank liquidity and its determinants in Romania. Procedia Economics and Finance, 3, 993-998.

Rashedul, H. M., \& Israt, R. M. (2012). Data envelopment analysis of banking sector in Bangladesh. Russian Journal of Agricultural and Socio-Economic Sciences, 5(5). 
Shingjergji, A., \& Hyseni, M. (2015). The determinants of the capital adequacy ratio in the Albanian banking system during 2007-2014. International Journal of Economics, Commerce and Management, 3(1), 1-10.

Sufian, F. (2010). Developments in the profitability of the Thailand banking sector: panel evidence from the post Asian crisis period. International Journal of Economics and Accounting, 1(1-2), 161-179.

Wasiuzzaman, S., \& Tarmizi, H. A. B. A. (2010). Profitability of Islamic banks in Malaysia: an empirical analysis. Journal of Islamic Economics, Banking and Finance, 6(4), 53-68. 